\title{
Trachea-guided generation: Déjà vu all over again?
}

Paolo Macchiarini, MD, PhD

See related articles on pages 124 and 147.
From the Department of Thoracic and Vascular Surgery, Heidehaus Hospital, Hannover Medical School, Hannover, Germany.

Received for publication Nov 12, 2003; revisions received Nov 19, 2003; accepted for publication Nov 24, 2003.

Address for reprints: Paolo Macchiarini, $\mathrm{MD}, \mathrm{PhD}$, Department of Thoracic and Vascular Surgery, Heidehaus Hospital (Hannover Medical School), Am Leineufer 70, 30419 Hannover, Germany (E-mail: pmacchiarini@compuserve.com).

J Thorac Cardiovasc Surg 2004;128:14-6

$0022-5223 / \$ 30.00$

Copyright (C) 2004 by The American Association for Thoracic Surgery

doi:10.1016/j.jtcvs.2003.11.069

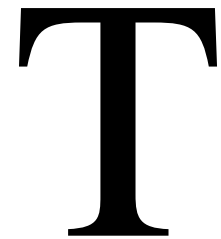

racheal surgery has matured to include techniques able to cure most lesions involving approximately half of the tracheal length in adults and probably a third in small children. Age, body build, local anatomy, type of pathology, and previous treatment may cause these limits of resection to fluctuate, but a safe primary reconstruction is almost always possible provided the surgeon respects the wellknown surgical principles and uses anatomic mobilization procedures. ${ }^{1}$ The complex problem of congenital tracheal stenosis has also been solved by slide tracheoplasty, ${ }^{2}$ and even those benign lesions that are too lengthy for safe reconstruction nowadays can be successfully managed in the long-term with T-tubes or stents. ${ }^{3}$ It therefore appears that the clinical need for tracheal replacement is restricted to unresectable diseases - such as tracheopathia osteoplastica, relapsing polychrondritis, Wegener granulomatosis, trauma and low-grade malignancies in adults, and tracheal agenesis in neonates ${ }^{4}$ - that are essentially treated with palliative measures and immunosuppression. Despite this, experimental research to generate a functional tracheal graft has been going on for a century and is currently under active investigation. Unfortunately, no predictable and dependable replacement has yet been found. ${ }^{5}$ This is not surprising, because an ideal graft must have some prerequisites: lateral rigidity and longitudinal flexibility, complete air tightness, biocompatibility, nonimmunogenicity, nontoxicity, resistance to bacterial colonization, freedom from the need for immunosuppression, permanent construction, ease of implantation, and the ability to provide a platform of ciliated respiratory epithelium resurfacing.

In this issue of the Journal, Kim and associates ${ }^{6}$ have combined the lessons learned from the past with the exciting research field of tissue engineering and experimentally developed a hybrid prosthetic graft that apparently fulfills almost all requirements for an ideal tracheal substitute. Conceptually, their working hypothesis is attractive. They first tissue engineered a viable autogenous mucosa by isolating abdominal skin epithelial cells and seeding them on a polylactic glycolic acid scaffold. Next, the autogenous mucosa was attached with biodegradable glue to the luminal surface of a porous prosthesis framework made up of polypropylene mesh reinforced with polypropylene rings. This artificial "hybrid" construct was then incubated for 1 week in the peritoneal cavity of the host to promote vascularization and maintain viability of the implanted tissue-engineered mucosa. One week later, the prosthesis along with the omentum was transposed into the thoracic cavity and used to replace a tracheal defect $5 \mathrm{~cm}$ in length (10 rings). Early ( 2 months) bronchoscopic results showed no anastomotic stenosis.

Tissue engineering applies the principles of engineering, material science, and biology toward the development of biologic substitutes that restore, maintain, or improve tissue function. ${ }^{7}$ This process of fabricating new, physiologic, functioning tissues may be obtained by the (1) guided tissue regeneration with engineered matrices alone, (2) injection of allogenic or xenogenic cells alone, or (3) use of cells seeded on or within matrices (cell matrix construct), being the latter two approaches the most common. The use of isolated cell or cell substitutes avoids potential surgical complications and allows cell manipulation before injection but has the drawbacks of possible rejection or loss of function. ${ }^{8}$ The use of seeded matrices, the most common method in tissue engineering, is particularly fascinating because these structures are biocompatible, bioabsorbable, nonimmunogenic, supportive of cell attachment and growth, and inductive of angiogenesis. They may be created either 


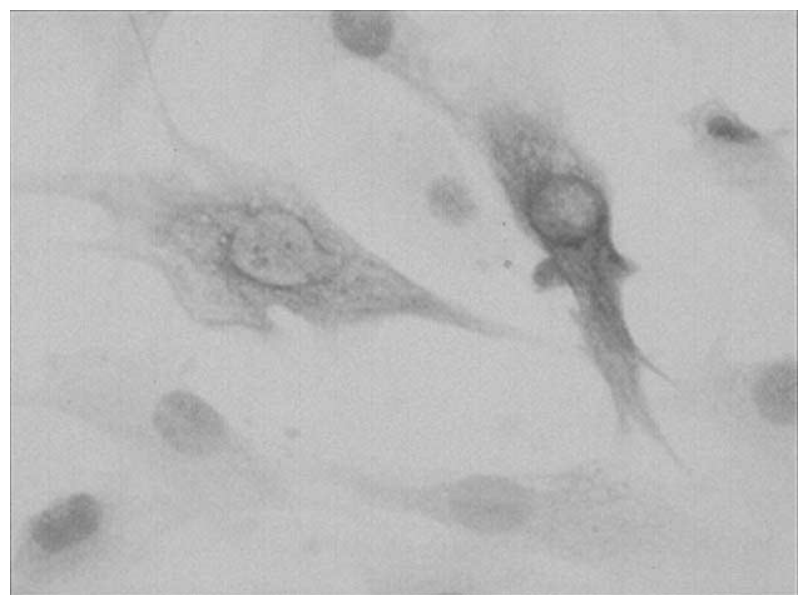

Figure 1. Chamber slide showing two porcine smooth myocytes after 2 weeks in culture ( $200 \times$ magnification).

by isolating the cells from host's body with a permeable membrane allowing exchange of nutrients (closed system) or by culturing in vitro the isolated cells and seeding them onto a scaffold, either synthetic or natural, that is implanted into the host after a given cultivation time (open system). ${ }^{9}$ Cells used in tissue engineering can be derived from numerous sources, including primary tissues, cell lines, and stem cells, and they may be allogenic, xenogenic, syngeneic, or autologous. Ideally, the cells should be easy to harvest, highly proliferative, nonimmunogenic, and able to differentiate into a variety of cell types with specialized functions. ${ }^{10}$ Having said that, it appears that the methodology used in Kim and colleagues' research ${ }^{6}$ is not tissue engineering but rather guided tracheal tissue generation, ${ }^{11}$ because the tissue-engineered mucosal framework "remodels" to achieve a function only after its implantation into the native tracheal bed, which ultimately serves as a natural "bioreactor." Isn't this like déjà vu to some extent? "A polypropylene mesh [déjà vu] was covered with a tissueengineered mucosa [new concept] used to replace $5-\mathrm{cm}$ tracheal length in dogs [déjà vu].",10

This study adds useful confirmation about the effectiveness of tissue engineering, but the data should be reviewed and interpreted cautiously. First, the authors provide no morphologic, functional, biochemical, and immunologic data supporting the generation of a respiratory mucosa and its viability during the study period. Second, it is well known that a tissue-engineered cellular graft of larger than $0.8 \mathrm{~mm}$ in diameter needs vascularization to maintain viability after implantation into the host. However, the revascularization process usually begins within the first 2 weeks and flourishes within the eighth week of implantation. ${ }^{12}$ One might therefore speculate that an implantation time of 1 week is almost certainly too short for sufficient revascularization of small-diameter grafts. Third, the authors argue
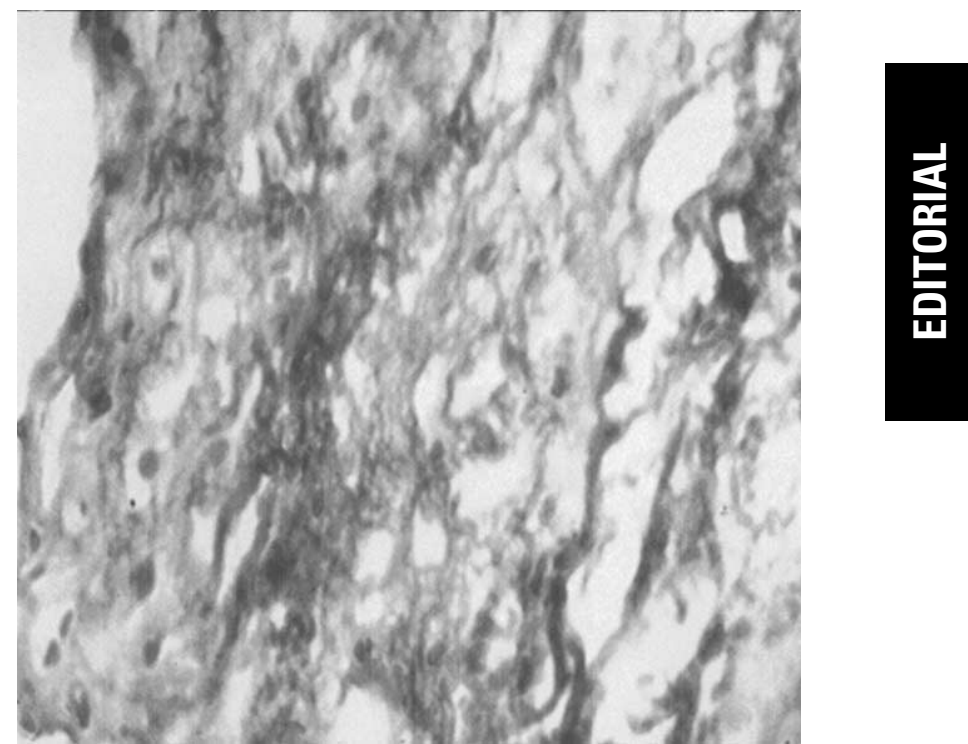

Figure 2. Tissue-engineered functional cartilage. Porcine chondrocytes seeded on 3-dimensional biologic matrix are located in lacunas and surrounded by newly synthesized collagen $(100 \times$ magnification). Western blots showed functioning chondrocytes.

that the hybrid prosthesis was implanted into the peritoneal cavity mainly to promote the vascularization of the mucosa. However, grafts implanted into the peritoneal cavity are covered with a heavy vascularized epithelial layer, representing a foreign-body reaction encapsulating the implanted graft. This reaction does not per se promote neoangiogenesis in the graft. ${ }^{13}$ Therefore it is highly questionable that both the mucosal lining was directly vascularized during its implantation into the peritoneal cavity and the hybrid prosthesis was viable and remained so at the time of transplantation. Fourth, assuming, however, that the luminal surface of the prosthesis was really covered with viable mucosal cells (because of its indirect vascularization with the omentum major), it is not unrealistic to speculate that it was either resurfaced with respiratory epithelium grown in from the anastomosis sites because of the short length $(5 \mathrm{~cm})$ of the implant $^{14}$ or the original autologous stratified squamous epithelium regenerated to ciliated columnar epithelium just because of the porous nature of the prosthesis used, a common observation in the past. ${ }^{5}$ This is of clinical concern because in the interval between the bioartificial graft implantation and successful graft regeneration the luminal surface of the tracheal implant does not possess the usual physiologic properties, ${ }^{15}$ rendering it more susceptible to inflammation, granulation tissue formation, infection, and erosion. We therefore look forward to the long-term results as to whether the respiratory epithelium reseeded the graft surface after implantation. Fifth, if transposed to the clinical scenario, the methods used would be inapplicable because 
the necessity of multiple general anesthetic procedures and two abdominal operations, the short length of transplanted grafts ( $5 \mathrm{~cm}$, which has no potential clinical use), and, most of all, the absence of an adequate blood supply, which has been the major hurdle of autotransplanted free tracheal segments of any significant length, despite muscular or omental pedicles. ${ }^{16}$

So, what can we learn from this and what implications does this study have for the current and future state of the art of tracheal transplantation? Surgically placed porous prostheses (with and without epithelialization) have been unsuccessful in human use ${ }^{16}$ basically because they are exposed to a contaminated interface between air, chronically repairing connective tissue, and epithelium. It is time to acknowledge that they are biologically incompatible, in contrast to vascular conduits placed in potentially sterile mesenchymal tissue. My laboratory has traditionally been interested in tracheal transplantation. After having experimentally developed the surgical technique for directly revascularizing long-segment $(9-11 \mathrm{~cm})$ tracheal allografts, ${ }^{17}$ we have shifted our efforts to the generation of a direct revascularized tissue-engineered trachea because of the obvious advantages that this emerging technology has relative to tracheal allotransplantation ${ }^{4}$ or any other available alternative. ${ }^{14}$ The article by Kim and associates ${ }^{6}$ suggests that engineering a "trachea" mucosa is feasible, shows the limitation of tissue generation, and provides definitive and indirect evidence that only a complete tissue-engineered graft may substitute functionally for the native trachea. However, this is the real "holy grail" of tracheal replacement. The ideal functioning substitute must exhibit longterm patency, and the critical issues in this area in many ways are influenced by biomechanics and function. One of the requirements is that it must avoid graft obstruction by cicatrization, which requires a respiratory epithelium-like inner lining (Video). It also must have mechanical strength sufficient to operate at inspiratory and expiratory pressures. Ideally, however, it must be more than the sum of these qualities. It also must have contractile properties that match those of the native trachealis muscle being replaced (Figure 1). Finally, to have a clinical impact it must be sufficiently long and adaptable to changing respiratory flow conditions
(Figure 2), a function which in itself can be viewed as biomechanical in nature. To achieve this requires having, as part of the construct, a blood supply. Only if an engineered tracheal substitute possesses all of these functional characteristics can one say that the functionality exhibited by a native trachea is being mimicked.

\section{References}

1. Grillo HC. The history of tracheal surgery. Chest Clin North Am. 2003;13:175-91.

2. Grillo HC, Wright CD, Vlahakes GJ, MacGillivray TE. Management of congenital tracheal stenosis by means of slide tracheoplasty or resection and reconstruction, with long-term follow-up of growth after slide tracheoplasty. J Thorac Cardiovasc Surg. 2002;123:145-52.

3. Wood DE. Airway stenting. Chest Clin North Am. 2003;13:175-91.

4. Macchiarini P. Tracheal transplantation: beyond the replacement of a simple conduit. Eur J Cardiothorac Surg. 1998;14:621-3.

5. Grillo HC. Tracheal replacement: a critical review. Ann Thorac Surg. 2002;73:1995-2004

6. Kim J, Suh SW, Shin JY, Kim JH, Choi YS, Kim H. Replacement of a tracheal defect with a tissue-engineered prosthesis: early results from animal experiments. J Thorac Cardiovasc Surg. 2004;128:124-9.

7. Langer R, Vacanti JP. Tissue engineering. Science. 1993;260:920-6.

8. Vacanti JP, Langer R. Tissue engineering: the design and fabrication of living replacement devices for surgical reconstruction and transplantation. Lancet. 1999;354(Suppl):S132-4.

9. Fuchs JR, Nasseri BA, Vacanti JP. Tissue engineering: a 21st century solution to surgical reconstruction. Ann Thoracic Surg. 2001;72:57791.

10. Marler JJ, Upton J, Langer R, Vacanti JP. Transplantation of cells in matrices for tissue engineering. Adv Drug Del Rev. 1998;33:165-82.

11. Nerem RM, Seliktar D. Vascular tissue engineering. Annu Rev Biomed Eng. 2001;3:225-43.

12. Walles T, Herden T, Haverich A, Mertsching H. Influence of scaffold thickness and scaffold composition on bioartificial graft survival. Biomaterials. 2003;24:1233-9.

13. Cebotari S, Walles T, Sorrentino S, Haverich A, Mertsching H. Guided tissue regeneration of vascular grafts in the peritoneal cavity. Circ Res. 2002;90:e71.

14. Macchiarini P, Candelier JJ, Coullin P, Guerra N, de Montpreville V, Dartevelle $\mathrm{P}$, et al. Use of embryonic human trachea grown in nude mice to repair congenital tracheal stenosis. Transplantation. 2000;70: 1555-9.

15. Roche N, Dusser D. Rôles physiologiques de l'épithélium respiratoire. Presse Med. 1994;23:1865-70.

16. Grillo HC. Tracheal replacement [letter]. J Thorac Cardiovasc Surg. 2003;125:975.

17. Macchiarini P, Mazmanian GM, de Montpreville VT, Dulmet E, Fattal M, Lenot B, et al. Experimental tracheal and tracheoesophageal allotransplantation. Paris-Sud University Lung Transplantation Group. J Thorac Cardiovasc Surg. 1995;110:1037-46. 